\title{
Permits vs. offsets under investment uncertainty
}

\author{
Nicolas Koch ${ }^{1, *}$, Wolf Heinrich Reuter ${ }^{2,3}$, Sabine Fuss ${ }^{1,2}$, Godefroy Grosjean ${ }^{1,4,5}$ \\ ${ }^{1}$ Mercator Research Institute on Global Commons and Climate Change (MCC), Torgauer Str. 12-15, 10829 Berlin, Germany \\ ${ }^{2}$ International Institute for Applied System Analysis (IIASA), Schlossplatz 1, 2361 Laxenburg, Austria \\ ${ }^{3}$ Vienna University of Economics and Business (WU), Welthandelsplatz 1, 1020 Vienna, Austria \\ ${ }^{4}$ Potsdam Institute for Climate Impact Research, Telegrafenberg A31, 14473 Potsdam, Germany \\ ${ }^{5}$ Technische Universität Berlin, Economics of Climate Change, Straße des \\ 17. Juni 145, 10623 Berlin, Germany \\ ${ }^{*}$ Corresponding Author: koch@mcc-berlin.net
}

\begin{abstract}
A global crediting mechanism would enable developing countries without binding emissions reduction targets to participate in the international carbon market. Linking the framework on Reducing Emissions from Deforestation and Forest Degradation (REDD+) as an offset program to major cap-and-trade programs is a particularly promising approach to increase both climate finance and cost-efficiency. However, the coexistence of permits and offsets also creates a classic case of interaction effects. In this paper, we explore how the availability of multiple compliance instruments affects energy investment incentives. Alternative trading and linkage schemes are compared using a real options model of firmlevel investment decisions under stochastic prices and the ability to delay investments. We first isolate the critical design factors that drive private investments in the energy sector. We then identify policy regimes that balance the different concerns in the polarized debate for and against the inclusion of forest carbon offsets.
\end{abstract}

\section{Introduction}

Since the signing of the Warsaw framework on Reducing Emissions from Deforestation and Forest Degradation (REDD+), the prospects for a large scale development of REDD+ credits have significantly improved (Recio, 2013). At the same time, the discussions regarding a top-down global carbon market have faded. In fact, many observers of international negotiations now argue in favor of hybrid international treaties combining both bottom-up and top-down approaches (Edenhofer et al., 2013; Ranson \& Stavins, 2014). While this could be achieved through full linking of existing emissions trading schemes, the political appetite for this approach in the short-term is currently not at its highest. This deadlock seems to reflect the major barriers that complicate full linking: the need to harmonize levels of ambition and to accept (possibly significant) financial flows between jurisdictions but also the fear of losing regulatory control and increasing vulnerability to external shocks (Flachsland et al., 2009; Green et al., 2014; McKibbin et al., 2008). Nonetheless, with the positive development at the $21^{\text {st }}$ Conference of the Parties (COP21) in Paris, it is also likely that further integration between emerging GHG pricing schemes in the world will occur and will be perceived as desirable (Bodansky et al., 2014). In addition, one may expect that developing economies will demand some degree of support for their 
mitigation efforts from the rest of the world, including financial transfers. The main tool so far for such purposes that linked fragmented carbon markets was the Clean Development Mechanisms (CDM) under the Kyoto Protocol. However, as this mechanism is currently in palliative care (Kossoy et al., 2015) REDD+ could become a new framework towards bottom-up integration of carbon markets.

REDD+ is a relatively low-cost mitigation option (Busch et al., 2009; Kindermann et al., 2008; Lubowski \& Rose, 2013) and, therefore, its integration in a global mitigation strategy could allow larger emissions reductions and lower overall abatement costs. One option is to link REDD+ as an emission reduction credit program unilaterally to major cap-and-trade programs in the EU, US, but also China and Korea (Angelsen \& Rudel, 2013). ${ }^{1}$ The crediting mechanism would enable major developing countries without binding caps to participate in the international carbon market (Tuerk et al., 2009). In addition, one-way linking would significantly strengthen the currently weak demand for REDD+ (Laing et al., 2015) and mobilize the funding needed to realize the REDD+ mitigation potential. ${ }^{2}$ This could also allow building operational best practices and the necessary institutions, in particular in developing countries (Green et al., 2014; Wehkamp et al., 2015). Such an incremental and polycentric approach to overcome multijurisdictional negotiations (Ostrom, 2009) could be a first step towards a global carbon markets in a more distant future (Green et al., 2014). Politically, unilateral linking might be more palatable as countries keep more control within their own carbon markets (Tuerk et al., 2009).

However, the inclusion of REDD+ in the global carbon markets is a highly controversial issue in the climate policy debate. The key concern is that the availability of low-cost REDD+ credits - due to the low marginal costs of reduced forest emissions - may 'flood' the compliance market and 'crowd out' socially optimal mitigation efforts in other sectors (Fry, 2008; Murray et al., 2009) as well as investments and research and development into low carbon technologies (Bosetti et al., 2011; Fuss et al., 2011). ${ }^{3}$ Such disincentives to mitigate and invest could in fact threaten the dynamic efficiency of the market and increase the overall costs of achieving long-term decarbonization targets. ${ }^{4}$ Therefore, it is of high importance to assess the relevant design factors that determine the impact of an inclusion of REDD+ credits in a mandatory pollution control system.

In this paper, we explore how the availability of multiple compliance instruments, permits and credits, affects an energy producer's incentive to invest in low-carbon technology. Alternative emissions trading schemes and linkage designs are compared using a real options model of firm-level investment decisions (Dixit \& Pindyck, 1994) characterized by dependent and uncertain price paths for permits and credits. More specifically, our model is calibrated to the stylized features of a wide range of existing

\footnotetext{
${ }^{1}$ Cap-and-trade systems set a binding, absolute cap on total emissions, but allow for trade of permits between regulated entities. In contrast, credit systems define a certain baseline, such as an absolute business-as-usual projection, and only allow emission reductions that go beyond this baseline to be used as sellable credits (often referred to as offsets).

${ }^{2}$ Otherwise international funding for REDD+ would have to be raised either in form of public funds (e.g., official development aid), voluntary contributions or a separate market for REDD credits. See for more details, (Angelsen \& Rudel, 2013).

${ }^{3}$ Looking at the experience of the EU ETS, the large import of CER credits is one of the factors often blamed for the price collapse (e.g. European Commission, 2014; Neuhoff et al., 2012). CER prices have indeed been persistently below EUA prices. Empirical evidence for this claim is however weak (Koch et al., 2014).

${ }^{4}$ Other concerns that are, however, outside the scope of the paper are the establishment of a reliable system to measure, report and verify (MRV) and the setting of appropriate reference levels, with associated issues of additionality, permanence and leakage (Kerr, 2013; Lubowski \& Rose, 2013).
} 
and emerging cap-and-trade programs in the EU, US, New Zealand and Korea. They differ inter alia in terms of price stabilization mechanisms (e.g. price floor) and credit quotas (e.g. $13.4 \%$ in EU ETS). ${ }^{5}$ In addition, we explore alternative REDD+ pricing schemes discussed in the literature (e.g. indexed to carbon prices or opportunity costs of conservation as in Engel et al., 2015) ${ }^{6}$ and how they affect the demand for REDD+ beyond the imposed quota by policy makers. Our aim is to identify linked policy regimes that balance the different concerns in the polarized debate for and against inclusion. This is undertaken by isolating the critical design factors that drive private investments into the transformation of the energy infrastructure.

In a nutshell, we model a representative agent in the energy sector who owns an old coal-fired power plant (as representative for cheap power plants with high emissions as in Szolgayova et al., 2008). This power plant can but does not have to be replaced by a wind park - representing all renewable technologies with high investment costs but no emissions. Similar to Fuss et al. (2011) the agent can surrender permits and offsets for compliance, but we introduce two novel model features consistent with real world policy schemes. First, the agent can decide how many REDD+ credits she will surrender, yet, this choice is subject to restrictions. Second, permit and credit prices are both assumed to be stochastic following two correlated Geometric Brownian Motions (GBM). Therefore, the REDD+ quota alone is not sufficient for explaining credit usage. We conduct several experiments using, amongst others, different values for the correlation parameter and the offset quota. We then deduce the agent's optimal strategy in terms of the chosen power plant type and the share of REDD+ credits. This enables us to explore how the policy design affects the agent's incentive either to invest in a lowcarbon power plant or to postpone such an investment due to the option value of the fossil-based power plant.

The remainder of the paper is structured as follows. Section 2 introduces the real option methodology and provides information on data used for calibration. In section 3, the results are discussed. Section 4 concludes with policy implications.

\section{Model section}

Consider an electricity producer with a finite planning horizon of 50 years $(T=50)$. The electricity producer owns an old coal fired power plant (as representative for cheap power plants with high emissions and production based on fossil fuels), which he can either continue or replace by an offshore wind park, representing all renewable technologies with high investment costs but no emissions and relatively lower operating costs. The electricity producer can only own one power plant in each time period.

The operating profit of the power plant at time $t$ depending on its type $\left(a_{t}\right)$ can be represented by Equation 1:

$$
\pi^{P P}\left(a_{t}, P_{t}^{E}\right)=Q \cdot P_{t}^{E}-F C\left(a_{t}\right)-Q \cdot O C\left(a_{t}\right)
$$

where $Q$ is the quantity produced by the power plant. We normalize the size of each of the different power plant types to an annual electricity output of 7,446 MWh per year, which corresponds to a capacity of $1 \mathrm{MW}$ at an availability factor of $85 \%$. Thus, $Q$ is independent of the chosen power plant

\footnotetext{
${ }^{5}$ See Hood (2010) and Kossoy et al. (2014) for a review of existing and emerging emissions trading programs.

${ }^{6}$ See Engel et al. (2008) for an overview.
} 
type. Furthermore, we assume a constant load factor for each power plant, which especially for renewable technologies might lead to a small positive bias (see e.g. Reuter et al., 2012; Szolgayova et al., 2008). $P^{E}$ is the constant price of electricity, which the electricity producer earns per unit produced. The fixed (investment) costs depending on the chosen power plant are denoted by $F C\left(a_{t}\right)$. We annualize the capital costs, representing a situation where the overnight construction costs are covered by a loan with annualized capital costs being the yearly instalments of such a loan at $5 \%$ interest. $O C\left(a_{t}\right)$ represents the (constant) operating costs of power plant type $a_{t}$. The fixed and operating costs are based on IEA (2010) and shown in Table 1.

Table 1 - Cost of electricity production depending on type of power plant

\begin{tabular}{|c|c|c|c|}
\hline Power plant type $\left(a_{t}\right)$ & $\begin{array}{l}\text { Annualized fixed } \\
\text { investment costs, } \\
F C\left(a_{t}\right)\end{array}$ & $\begin{array}{l}\text { Operating costs, } \\
O C\left(a_{t}\right)\end{array}$ & $\begin{array}{l}\text { Greenhouse gas } \\
\text { emissions per MWh, } \\
G H G\left(a_{t}\right)\end{array}$ \\
\hline Coal-fired power plant & 60,825 US\$/year & 28 US\$/MWh & $6,552 \mathrm{t} \mathrm{CO}_{2} /$ year \\
\hline Wind farm & 312,563 US\$/year & 23.63 US\$/MWh & $0 \mathrm{t} \mathrm{CO}_{2} /$ year \\
\hline
\end{tabular}

Notes: All types are normalized to an annual electricity output of 7,446 MWh, calculated from IEA (2010)

\subsection{Regulated market environment}

In our setting, the electricity producer is placed in a regulated market environment, similar to the EU ETS scheme. Thus the electricity producer is obliged to cover his greenhouse gas emissions, which are emitted during the production process. In our case the electricity producer is offered two options to cover his emissions:

1. Carbon permits

2. REDD+ credits

The prices of both certificates are assumed to be stochastic and correlated, with $P_{t}^{P}$ being the price of carbon permits at time $t$ and $P_{t}^{R}$ the price of REDD+ credits. For each unit of emission the electricity producer needs to buy either a corresponding unit of carbon permit or REDD+ credit. Note that we use the terms credits and offsets interchangeably. The total cost from covering carbon emissions of the electricity producer can be represented as $C C$ in Equation 2:

$$
C C\left(a_{t}, \delta_{t}, P_{t}^{P}, P_{t}^{R}\right)=Q \cdot G H G\left(a_{t}\right) \cdot\left[\left(1-\delta_{t}\right) \cdot P_{t}^{P}+\delta_{t} \cdot P_{t}^{R}\right]
$$

where $G H G\left(a_{t}\right)$ is the relative amount of greenhouse gas emissions emitted per unit of output $(Q)$ depending on the type of power plant used $\left(a_{t}\right) . \delta_{t}$ is the share of total emissions covered by REDD+ credits at time $t$. Consistent with real world trading schemes, policy makers can restrict the amount of REDD+ credits by setting a relative quota $\left(\delta_{t} \leq \bar{\delta}^{R}\right)$.

An important model feature is that we endogenize the REDD+ usage parameter $\delta_{t}$, i.e. the agent can decide how many REDD+ credits she will surrender. Prior modelling builds on the assumption that all available offsets are used by the firm (Fuss et al., 2011) as it is usually argued that firms have strong incentives to surrender the maximum amount of credits allowed, precisely because credits are cheaper than permits (e.g. Fry, 2008). However, such offset usage behavior is inconsistent with empirical 
evidence. For instance, Naegele (2015) shows that almost a quarter of the regulated entities in the EU ETS do not surrender any CDM offsets and only 50\% of the firms surrender CDM offsets up to the maximum allowed (see also Braun et al., 2014). In our model it is the stochastic nature of permit and offset prices that drives the offset usage behavior.

\subsection{Price processes}

As we investigate the consequences of different carbon certificate price scenarios, we do not want parts of our results driven by a stochastic electricity price. Therefore, we assume that the electricity price $\left(P_{t}^{E}\right)$ is constant over the planning horizon at $50 \mathrm{US} \$ \mathrm{MWh}$, which falls within the range of current spot market prices for the major EU exchanges.

The prices of carbon permits and REDD+ credits on the other hand are assumed to be stochastic and correlated. Equation 3 shows the price processes following Geometric Brownian Motions (GBM) for carbon permits $\left(P_{t}^{P}\right)$ and REDD+ credits $\left(P_{t}^{R}\right)$.

$$
\begin{aligned}
& d P_{t}^{P}=\mu^{P} P_{t}^{P} d t+\sigma^{P} P_{t}^{P} d W_{t}^{P} \\
& d P_{t}^{R}=\mu^{R} P_{t}^{R} d t+\sigma^{R} P_{t}^{R} d W_{t}^{R}
\end{aligned}
$$

Where $\mu^{P}$ and $\mu^{R}$ are the drift of the price process respectively, $\sigma^{P}$ and $\sigma^{R}$ are volatility parameters and $d W_{t}^{P}$ and $d W_{t}^{R}$ represent the increment of a Wiener process for carbon permits and REDD+ credits, respectively. We assume the two increments of the Wiener processes to be correlated, where the correlation parameter is denoted by $\rho$.

The respective parameters used in our analysis are shown in Table 2. Given the lack of reliable longterm data for carbon prices, ${ }^{7}$ we resort to shadow price calculations taken from the recent IPCC AR5 report. The IPCC shadow price paths are based on multiple Integrated Assessment Models (IAMs) for a $450 \mathrm{ppm}$ GHG stabilization target, which is associated with a relatively higher probability of maintaining warming below 2 degrees $C$ above pre-industrial levels. It is important to note that these models are based on different assumptions on stylized socioeconomic factors (such as demographic transformation or technological developments). For the drift estimate, we use the average trend implied by the shadow price trajectories across models up to 2050, which is about $7 \%$. For the volatility parameter, we base the estimate on the spread of the different scenarios involved (i.e. standard deviation across IAMs, which amounts to $18 \%$ ). Thus, we implicitly assume that the IAM scenarios span the relevant states of the world. However, we acknowledge that this might deviate from reality to some extent and thus conduct additional experiments with regards to the uncertainty parameter to also account for a regime with significantly lower as well as higher volatility (set arbitrarily to $10 \%$ and $30 \%)$. Motivated by the fact that offset schemes such as REDD+ by their nature also involve project risks (Dormady \& Englander, 2015) we consistently assume a higher volatility for credits. More specifically, the volatility increment (by factor $1 / 3$ ) is aligned with the observable difference between price fluctuations in existing permit (EU ETS) and credit (CDM) markets.

Finally, the correlation parameter is calibrated to reflect two distinct market scenarios. A high correlation between permit and credits prices would be present if the REDD+ scheme was integrated

\footnotetext{
${ }^{7}$ Observable market prices for carbon in existing cap-and-trade programs, such as the EU ETS, have been volatile and low (Newell et al., 2014). It is highly questionable whether these market prices ensure the attainment of long-term climate policy goals (Grosjean et al., 2014; Knopf et al., 2014) .
} 
in the global carbon market as it is currently the case for CDM. A low correlation would be present if REDD+ remains a segmented market, in which REDD+ prices mainly reflect opportunity costs (OC) of other land use (i.e. forgone agricultural returns).

Table 2 - Parameters of price processes

\begin{tabular}{|l|lllllll|}
\hline & Starting price & Drift $(\mu)$ & \multicolumn{2}{l}{ Volatility $(\sigma)$} & & \multicolumn{2}{c|}{ Correlation $(\rho)$} \\
& per ton $\mathrm{CO}_{2}$ & & Base & Low & High & Low & High \\
\hline Permits & 10 US\$ $^{8}$ & $7 \%^{9}$ & $18 \%^{10}$ & $10 \%$ & $30 \%$ & $0.1^{11}$ & $0.8^{12}$ \\
Credits & 4 US\$ & $7 \%^{14}$ & $24 \%^{15}$ & $13 \%$ & $40 \%$ & & \\
\hline
\end{tabular}

In addition to various assumptions about the price process and the correlation of the two, policy makers can decide to implement price floors or bands to steer the investment activity of producers. Equation 4 incorporates the minimum $\left(\underline{P}^{P}, \underline{P}^{R}\right)$ and maximum $\left(\bar{P}^{P}, \bar{P}^{R}\right)$ prices set by policy makers.

$$
\begin{aligned}
& P_{t}^{P}=\min \left(\max \left(P_{t}^{P}, \underline{P}^{P}\right), \bar{P}^{P}\right) \\
& P_{t}^{R}=\min \left(\max \left(P_{t}^{R}, \underline{P}^{R}\right), \bar{P}^{R}\right)
\end{aligned}
$$

\subsection{Optimal control problem}

The total profit of the electricity producer at time $t$ is represented in Equation 5:

$$
\begin{aligned}
\pi\left(a_{t}, \delta_{t}, P_{t}^{E}, P_{t}^{P}, P_{t}^{R}\right) & =\pi^{P P}\left(a_{t}, P_{t}^{E}\right)-C C\left(a_{t}, \delta_{t}, P_{t}^{P}, P_{t}^{R}\right) \\
& =Q \cdot\left[P_{t}^{E}-O C\left(a_{t}\right)-G H G\left(a_{t}\right) \cdot\left[\left(1-\delta_{t}\right) \cdot P_{t}^{P}+\delta_{t} \cdot P_{t}^{R}\right]\right]-F C\left(a_{t}\right)
\end{aligned}
$$

Under the assumptions described above the producer's problem can be formulated as

$$
\begin{aligned}
\max _{a_{t}, \delta_{t}} E & {\left[\sum_{t=1}^{T} \frac{1}{(1+r)^{t}} \pi\left(a_{t}, \delta_{t}, P_{t}^{E}, P_{t}^{P}, P_{t}^{R}\right)\right] } \\
a_{0} & =1 \\
a_{t} & =a_{t-19} \forall t
\end{aligned}
$$

\footnotetext{
${ }^{8}$ Based on the price floor in the Californian ETS and roughly in line with 2010 price in REMIND 1.5 AMPERE2-450FullTech-OPT (=12\$/ton $\mathrm{CO}_{2}$ ) and other models.

9 Based on the average exponential growth rate of shadow prices in the following models: REMIND 1.5 (AMPERE2-450-FullTech-OPT); MESSAGE V.4 (AMPERE2-450-FullTech-OPT); IMAGE 2.4 (AMPERE2-450-FullTechOPT); GCAM 3.1 (LIMITS-450). We exclude those models that predict skyrocketing shadow prices (namely AIMEnduse, WITCH_LIMITS and POLES EMF27).

${ }^{10}$ Based on the shadow price volatility across models specified above.

${ }^{11}$ Historical correlation between soy and EUAs over the period 2008-2012 is 0.06. Source: ICE Futures

12 Historical correlation between EUAs and CERs over the period 2008-2012 is 0.74. Source: ICE Futures

${ }^{13}$ Based on 2010 prices for forestry offsets according to Cal ARB.

14 The value of $7 \%$ is consistent with a REDD price of $\sim 16$ in $2030=$ global average price in Kindermann et al. (2008) for a $50 \%$ reduction in deforestation.

${ }^{15}$ We assume that the credit volatility is by one third higher than the carbon shadow price volatility. The factor $1 / 3$ reflects the observed higher price volatility of CERs over EUAs. Source: ICE Futures
} 


$$
\begin{aligned}
& \delta_{t} \leq \bar{\delta}^{R} \\
& P_{t}^{E}=\overline{P^{E}} \\
& d P_{t}^{P}=\mu^{P} P_{t}^{P} d t+\sigma^{P} P_{t}^{P} d W_{t}^{P} \\
& P_{t}^{P}=\min \left(\max \left(P_{t}^{P}, \underline{P}^{P}\right), \bar{P}^{P}\right) \\
& d P_{t}^{R}=\mu^{R} P_{t}^{R} d t+\sigma^{R} P_{t}^{R} d W_{t}^{R} \\
& P_{t}^{R}=\min \left(\max \left(P_{t}^{R}, \underline{P}^{R}\right), \bar{P}^{R}\right) \\
& \operatorname{Corr}\left(d W_{t}^{P}, d W_{t}^{R}\right)=\rho
\end{aligned}
$$

where $r$ is the subjective discount rate and $\frac{1}{(1+r)^{t}}$ is the discount factor, i.e. the factor by which future profits to be received at time $t$ must be multiplied in order to obtain the present value and which we fix at $5 \%$ for our analysis as is common practice in such analyses (cf. Reuter et al., 2012). The direction of the results does not change significantly for variations of this, however.

$P_{t}^{P}$ and $P_{t}^{R}$ are the state variables and $a_{t}$ and $\delta_{t}$ the control variables that represent the choice of power plant type electricity producer and the share of REDD+ credits purchased respectively. Note that investment into a power plant is a long-lived investment, which we take into account by allowing for scrapping of old equipment only after 20 years.

The producer thus needs to find the optimal strategy combinations $\left\{a_{t}, \delta_{t}\right\}_{t=1}^{T}$. The optimum decision in each year can be obtained recursively by solving the Bellman equation:

$$
V_{t}\left(P_{t}^{P}, P_{t}^{R}\right)=\max _{a_{t}, \delta_{t}}\left\{\pi\left(a_{t}, \delta_{t}, P_{t}^{E}, P_{t}^{P}, P_{t}^{R}\right)+(1+r)^{-1} E\left[V_{t+1}\left(P_{t+1}^{P}, P_{t+1}^{R}\right) \mid P_{t}^{P}, P_{t}^{R}\right]\right\}
$$

The equation can be solved by recursive dynamic programming. We then use the matrix of optimal decisions for each combination of states to derive statistics for the results. In particular, we simulate 10,000 price paths in order to obtain distributions of the investment frequencies and the associated profits, for example.

\section{Results}

\subsection{Benchmark simulations: basic economics of permit-offset linkage}

To begin with, we examine model settings with the full (unrestricted) inclusion of REDD+ offsets in the cap-and-trade program. We simulate these unrestricted settings under different market environments - i.e. permit and REDD+ price regimes - and compare our simulation results to a corresponding scenario with no offsets as a benchmark (later denoted as "No REDD+" scenario). Our emphasis in this first results section is on advancing the understanding about how the market environment independent of policy design - determines the extent to which (i) low-carbon technology is crowded out (3.1.1) and (ii) REDD+ can be helpful in hedging the transition from coal to wind (3.1.2).

Six market environment scenarios were constructed that result from the combination of different volatility and correlation regimes for permit and offset prices (Table 3). First, we consider the three alternative volatility levels for the two certificate price processes discussed above: (a) low volatility, (b) medium volatility, and (c) high volatility regime (see Table 2 for the specific parameter calibration). Second, as already outlined, we considered two alternative correlations between the two certificate 
prices: (1) We would observe a high positive correlation between permit and REDD+ prices if REDD+ schemes were integrated in the global carbon market as it is currently the case for CDM. ${ }^{16}$ This would most likely result in strong co-movements of permit and offset prices (in the following "market-based REDD+"). (2) A low positive correlation would reflect the situation of a segmented sectoral REDD+ market, in which REDD+ prices mainly reflect landowners' opportunity costs $(\mathrm{OC})$ of conserving forest (i.e. forgone agricultural returns). This "OC-based REDD+" approach would imply a weak price dependency between permits and offsets.

Our baseline is the medium volatility and high correlation combination (S-1 in Table 3) which reflects a market-based REDD+ approach and a price volatility in line with the spread over current predictions by IAMs.

Table 3 - Overview of price scenarios

\begin{tabular}{|c|c|c|c|}
\hline & \multicolumn{2}{|c|}{ Correlation regime } \\
\hline & & High & Low \\
\hline \multirow{3}{*}{ 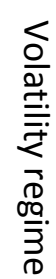 } & Medium & $\begin{array}{l}\text { Market-based REDD+ } \\
\text { (S-1) }\end{array}$ & $\begin{array}{l}\text { OC-based REDD+ } \\
(\mathrm{S}-2)\end{array}$ \\
\hline & Low & $\begin{array}{l}\text { Market-based REDD+/ low uncertainty } \\
(\mathrm{S}-3)\end{array}$ & $\begin{array}{l}\text { OC-based REDD+/ low uncertainty } \\
\text { (S-4) }\end{array}$ \\
\hline & High & $\begin{array}{l}\text { Market-based REDD+/ high uncertainty } \\
(\mathrm{S}-5)\end{array}$ & $\begin{array}{l}\text { OC-based REDD+/ high uncertainty } \\
(\mathrm{S}-6)\end{array}$ \\
\hline
\end{tabular}

\subsubsection{Investment behavior}

We first address the question how investment behavior and, in particular, the transition to wind energy is influenced by the (unrestricted) inclusion of REDD+ credits. Figure 1 presents the simulated frequency of wind investment over the planning horizon for the six market environment scenarios S-1 to S-6 (colored lines). To facilitate comparisons, we also plot the results of our benchmark model without offsets (black line). ${ }^{17}$

A comparison of the settings with and without the full inclusion of REDD+ illustrates the crowding-out effect of relatively cheap offsets: while investment in wind is increasing over time in both cases, the speed of transition as well as the magnitude of wind investments are higher when the firm does not have the option to use REDD+ credits. For instance, under the medium volatility regime, without REDD+, investment into wind starts after period 5 and reaches about $85 \%$ at the end of the planning horizon, while with REDD+, investments unfold only after period 10 and the wind investment share remains close to $50 \%$.

However, a second important finding is that the strength of crowding out effect hinges critically on the volatility of the two certificate prices. We observe a significantly higher (lower) wind investment probability under the low (high) volatility regime. In fact, with less volatile permit and REDD+ prices, the wind investment share also reaches about $85 \%$ (as in the case without REDD+ in the medium

\footnotetext{
${ }^{16}$ It is noteworthy that market integration is ultimately the result of (several) policy decisions to accept offsets in compliance markets. This implies also that the acceptance of offsets in a single and relatively small market (say Swiss ETS) would not lead to integrated markets.

${ }^{17}$ For the sake of brevity, we only show the no REDD+ case for the medium volatility regime.
} 
volatility regime). Still, the transition to the clean technology is delayed until around period 20 as the possibility to resort to REDD+ credits gives the investor the flexibility to reap the option value of delaying the transition. In contrast, a market environment with highly volatile permit and credit prices bears the risk of a long-term carbon lock-in, which is reflected by our finding that the wind investment frequency in the high-volatility scenarios stagnates at around $10-20 \%$. An important side question is whether permit or credit price fluctuations drive the volatility effect that we observe with respect to investment. To clarify, we also run simulations reducing only the permit or credit price volatility. Figure A1 in the appendix shows that it is, indeed, the REDD+ price volatility that is almost exclusively driving the result, while the impact of permit price variability is negligible.

\section{Figure 1 - Investment probability}

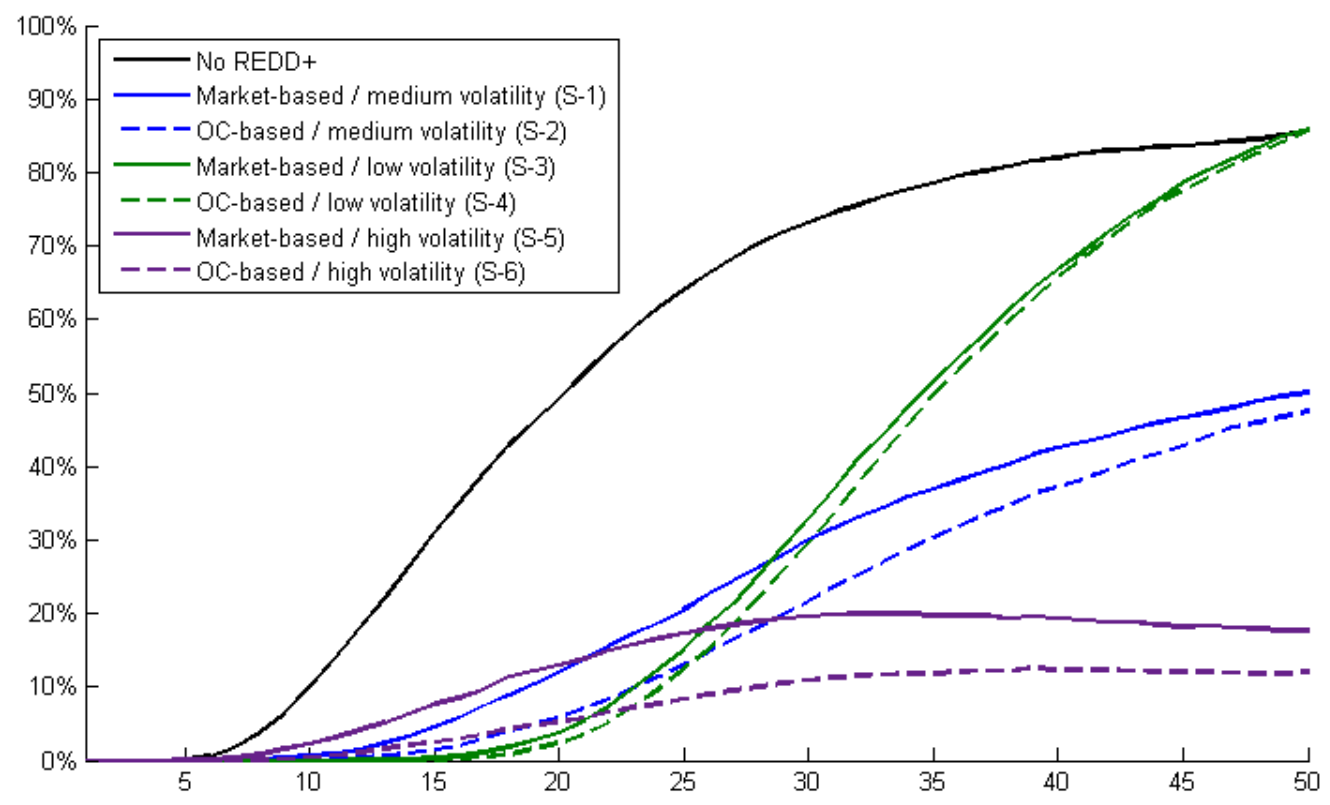

The impact of price volatility on the investment behavior is obviously what we would expect from real options theory (Dixit \& Pindyck, 1994): high uncertainties about the future path of carbon prices induce investors to wait until uncertainty has been resolved (Fuss et al., 2009). Or, to put it in other words, investors will be more willing to invest into capital-intensive low-carbon technologies if carbon prices are more certain. Yet, we believe that this result is highly underappreciated in the REDD+ controversy that fails to relate the strength of the crowding-out effect to the state of price volatility. In addition, we have shown that it is mainly the credit price variability that matters. Since credits are less expensive than permits, firms will in general have incentives to use credits for compliance, which in turn explains why credit price uncertainty is the critical factor for investment decisions. Acknowledging the volatility effect would result in a more balanced view on the adverse impact of REDD+ on low-carbon investments. In addition, it has an important policy implication, since it indicates that specific price stabilization mechanisms are more likely to be effective in inducing low-carbon investment than excluding REDD+ completely as a compliance option. We will explore this policy option in 3.2.

The third interesting finding from Figure 1 is that the degree of correlation between the two price processes has only a modest impact on the amount of wind investment. In general, we observe more wind investment under the high-correlation regime (i.e. in the case of market-based REDD+) and this effect is more pronounced in more volatile price regimes. However, the correlation effect remains in 
the single digits (2-9\%) and almost disappears in the low-volatility setting. Our finding is consistent with the standard real option prediction: under a low price correlation (i.e. in the case of OC-based REDD+) offset usage becomes more attractive because it may offer risk diversification opportunities (that, in turn, increase with volatility) and, thus, the crowding out of wind investment is more pronounced. The policy implication from this observation is that a market-based (rather than OCbased) REDD+ mechanism is more likely to be effective in inducing low-carbon investments.

Finally, the REDD+ offset usage behavior in our simulations is noteworthy. As discussed above, our model does not deterministically imply that all available offsets are used by the firm. Instead, our simulations rather suggest mixed strategies in REDD+ usage, which is in line with empirical findings in Naegele (2015) and Braun et al. (2014). Figure 2 shows our results for the offset usage in the baseline scenario (S-1). ${ }^{18}$ Using all credits is a dominant strategy in the early periods of the 50 -year planning horizon. However, the firm gradually switches to a strategy of using some but not all REDD+ credits. Finally, towards the end of the planning period we find a gradual phase-out of credit usage and using no credits becomes the dominant strategy, as the transition to wind gets completed.

\section{Figure 2 - Variation in REDD+ usage with market-based REDD+ and medium volatility}

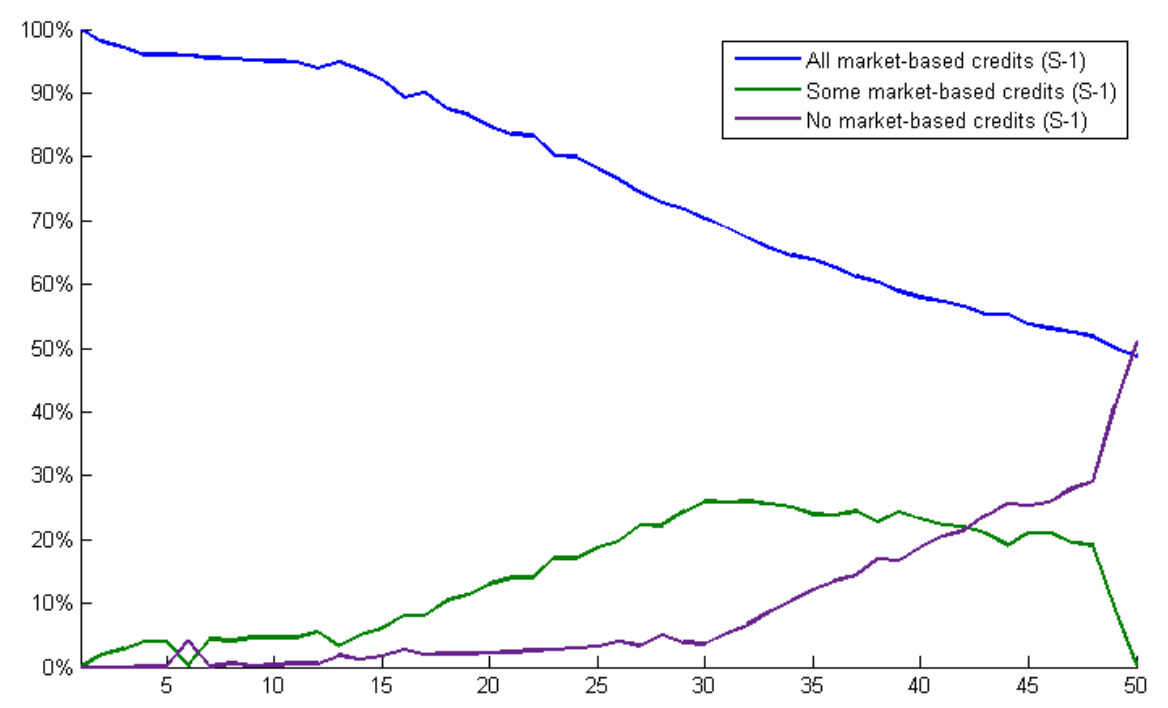

\subsubsection{Profit distribution}

While analyzing the impact of low-carbon investment is important from the perspective of a policymaker, who wants to effectively reduce emissions, the framework used here also enables us to say something about the costs and benefits of firms of doing so in different ways. Therefore, in addition to the (adverse) effect on wind investments, we seek to shed light on the (favorable) risk hedging effect of REDD+. In fact, Fuss et al. (2011) show that the inclusion of REDD+ in an emissions trading program can help to smooth out carbon price fluctuations, thereby reducing the risks that producers might be exposed to. Our simulations reinforce this finding and provide further insights into the role of the market environment in terms of volatility and correlation regimes for permit and offset prices.

Figure 3 shows the profit distributions for the case without an REDD+ offset scheme (Panel A) and for several cases where REDD+ credits can be bought (Panel B, C, and D). The figure clearly shows that the

\footnotetext{
${ }^{18}$ Results for the other market environment scenarios are qualitatively very similar and not reported for the sake of brevity.
} 
inclusion of REDD+ has a positive effect on profits: not only the average level of profits increases significantly but also the risk (i.e. standard deviation) associated with the profit flows decreases. As expected, we find a more narrow profit distribution in the setting with a low price volatility (relative to the medium volatility regime; see Panel $B$ and D). In line with expectations, we also find that the risk diversification effect is (slightly) more pronounced under a low-correlation regime (Panel C). In other words, profits are more certain under an OC-based REDD+ approach but the effect of the permit-credit correlation in general remains limited.

\section{Figure 3 - Profit distributions}

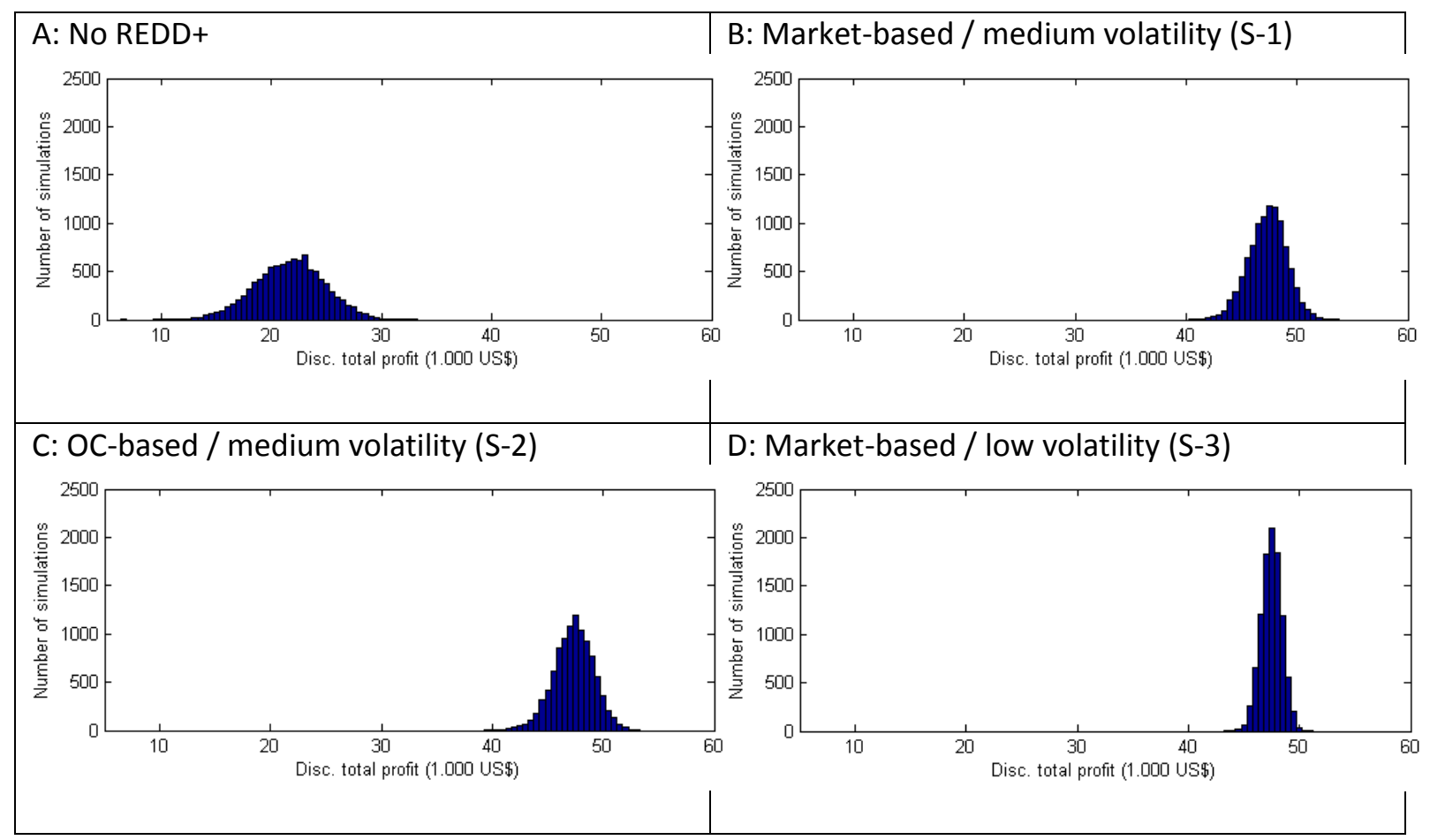

\subsection{Policy simulations: design options for permit-offset linkage}

Subsequently, we examine model settings with specific policy options that can be introduced when a REDD+ offset scheme and a cap-and-trade program are linked. Our emphasis in this part of the results section is on identifying policy regimes that may balance the adverse crowding-out effect with the favorable risk hedging effect of REDD+. To this end, we first deviate from the prior assumption of a full and unrestricted inclusion of REDD+ offsets. Instead, we introduce offset quotas (3.2.1). Second, we introduce price stabilization mechanisms with both a price floor and a price ceiling for certificates, which is a widely unexplored policy option in the context of permit-offset linkage (3.2.2). Finally, we combine both policy options and explore the effects of a policy regime with price collar and offset use limitations (3.2.3). All following experiments are built on the baseline scenario S-1, reflecting a marketbased REDD+ approach and price volatility in line with IAM predictions.

\subsubsection{Quota policy}

We have assumed hitherto that the offset usage is not restricted by policymakers. We now extend the basic model allowing for offset quotas. In fact, the full inclusion of REDD+ or other offsets is rarely observed in real-world cap-and-trade programs. Instead, most existing and planned cap-and-trade schemes restrict the quantity of offsets usable by firms. Offset quotas are mainly motivated as a means 
of ensuring that the bulk of emission reduction is achieved within the emissions trading system (Trotignon, 2012).

Table 4 gives an overview of offset entitlement rules in different cap-and-trade programs. Although the exact definition of quantity limits varies across programs, we generally observe a relatively low offset quota between around $3 \%$ and $13 \%$ of the cap in almost all legislated programs. The New Zealand Emissions Trading Scheme (NZ ETS) is the only legislated program with unlimited offset usage. ${ }^{19}$ Interestingly, the offset quota of $30 \%$ in the proposed federal US cap-and-trade system - the Waxman-Markey bill - was relatively high. A high offset quota of up to $50 \%$ is also planned in a future trading phase (2021-2025) of the Korean ETS. Similarly, Brazil and Mexico commit to emissions reductions through avoided deforestation in their Intended Nationally Determined Contributions (INDCs) and relatively high offset quotas could be expected for potential trading or tax schemes in these countries.

Table 4 - Overview of quota scenarios

\begin{tabular}{|l|lll|}
\hline REDD+ quota & Example & & \\
\hline$\leq 5 \%$ & Regional Greenhouse Gas Initiative (RGGI) & {$[2009-]$} & $3.3 \%$ \\
\hline$\leq 10 \%$ & California Cap-and-Trade Program & {$[2013-]$} & $8 \%$ \\
& EU ETS & {$[2013-2020]$} & varies \\
& Korean ETS & {$[2015-2020]$} & $10 \%$ \\
& Swiss ETS & {$[2008-]$} & $8 \%$ \\
& Quebec Cap-and-Trade System & {$[2013-]$} & $8 \%$ \\
\hline$\leq 15 \%$ & Australian Clean Energy Act & {$[2012-]$} & $12.5 \%$ \\
& EU ETS & {$[2008-2012]$} & $13.4 \%$ \\
\hline$\leq 30 \%$ & US Waxman-Markey bill & {$[2013]$} & $30 \%$ \\
\hline$\leq 50 \%$ & Korean ETS & {$[2021-2025]$} & $50 \%$ \\
\hline $100 \%$ & New Zealand ETS & {$[2008-]$} & unlimited \\
\hline
\end{tabular}

Source: (ICAP, 2015; Newell et al., 2014; Ranson \& Stavins, 2014)

In order to reflect the observed quota policy in our modeling, we implement four stylized policy scenarios with a 5\%, 10\%, 30\% and 50\% offset quota. Panel A of Figure 4 shows how the investment behavior is influenced by the existence of an offset quota by comparing the four quota simulations with the no-quota baseline and the no-offset scenario. The key finding from this experiment is that offset use limitations significantly reduce the crowding-out effect of REDD+. With a relatively low quota, as legislated in most ETS, the crowding-out risk is indeed negligible. Under a $10 \%$ offset quota, the wind investment share throughout the planning horizon is very close to the case without REDD+. Interestingly, we observe only a slightly higher wind investment probability under a 5\% quota.

\footnotetext{
${ }^{19}$ This policy design can partly be explained by the central fact that in New Zealand's program no auctions are held and regulated firms comply with any unmet permit need by purchasing offsets.
} 
Figure 4 - Investment probability under different policy scenarios

Panel A: with REDD+ quota

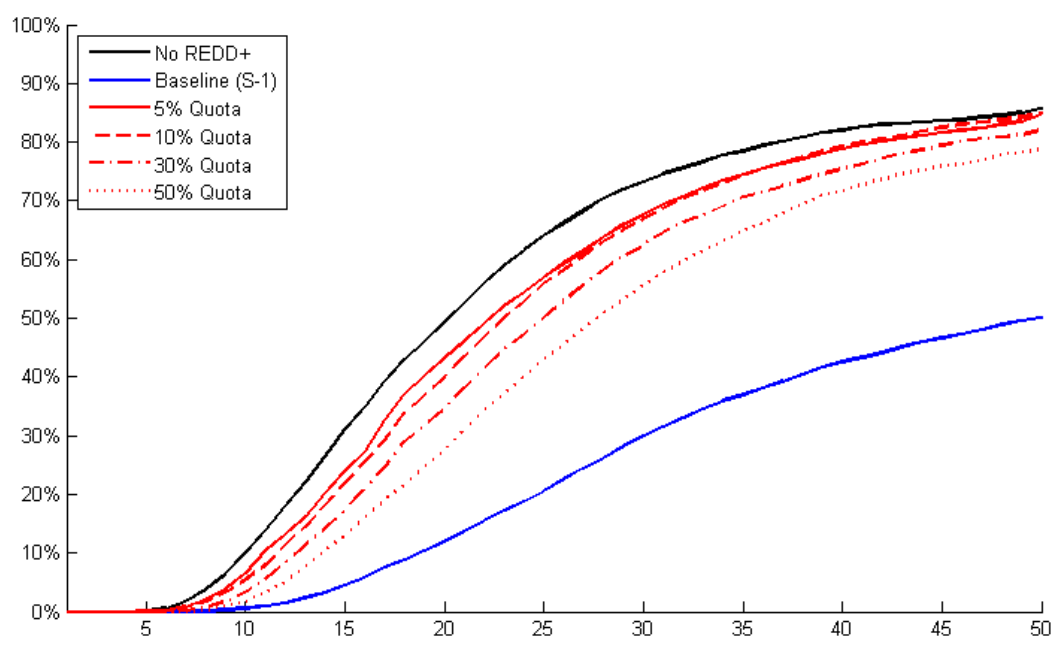

Panel B: with price collar

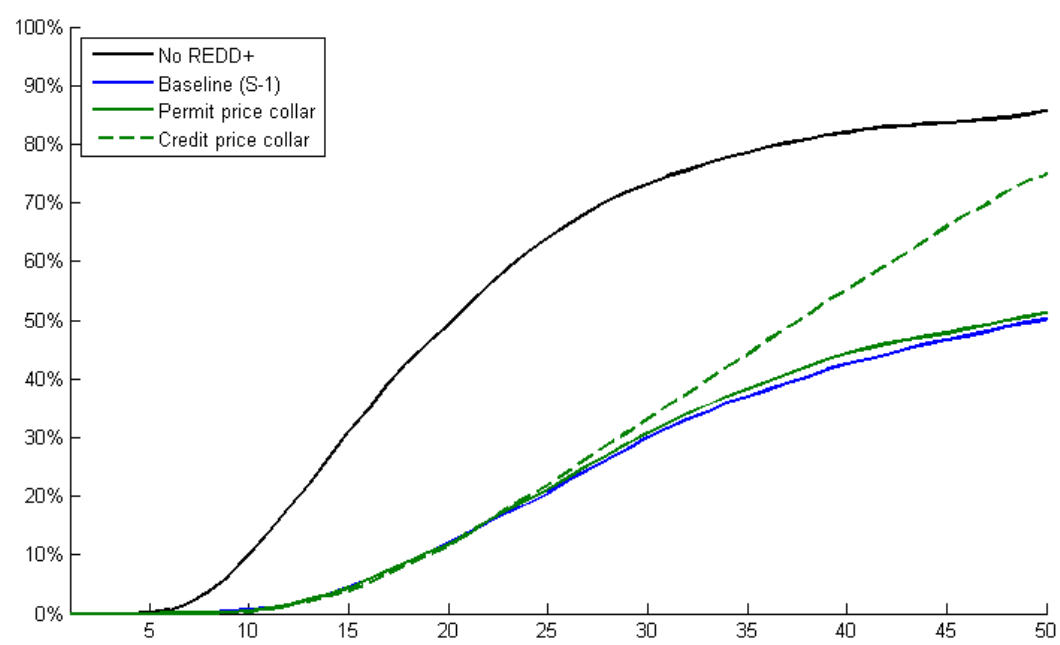

Panel C: with quota and price collar

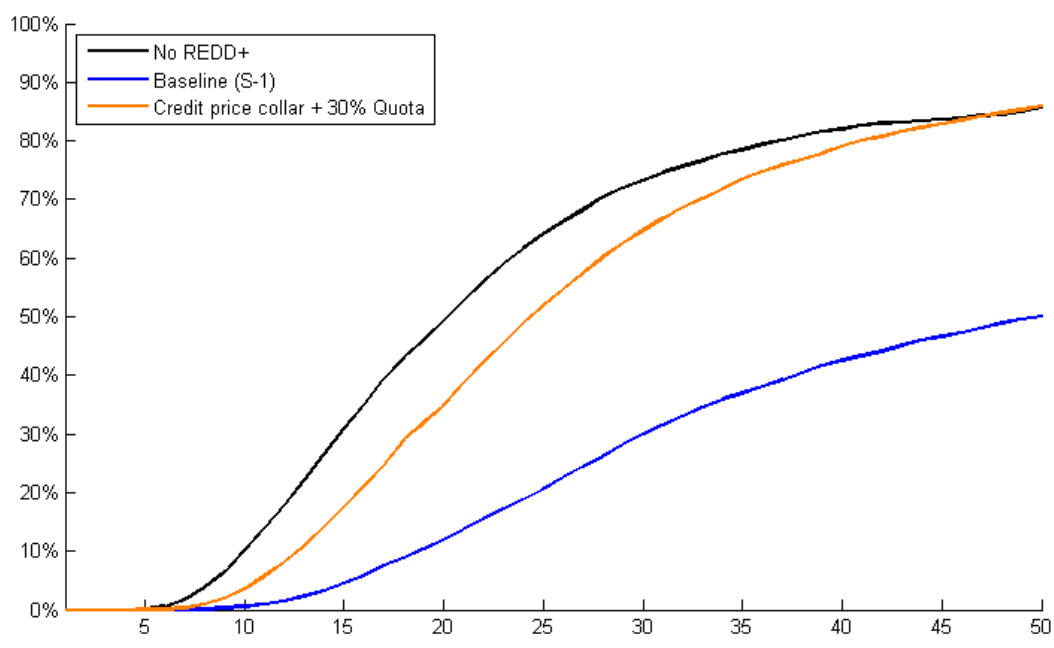


This has important policy implications: the benefits of introducing very low quotas or decreasing the quota from an already low level can be limited in terms of preventing crowding-out effects. Our simulations indeed suggest that $10 \%$ would be a sufficient restriction if policymakers are concerned about the crowding-out of low-carbon investments. While a relatively low quota would not stipulate more wind investments, it would, however, restrict the beneficial risk hedging effect thus decreasing the cost of the transition to low-carbon technologies to society. ${ }^{20}$ To illustrate this trade-off, Panel A of Figure 5 shows the profit distribution in a setting with a $10 \%$ and $50 \%$ quota (in addition to the benchmark without REDD+). The simulations highlight that the level of profits is increasing and the risk of profits is decreasing in the offset quota. In fact, the profit distribution with a $50 \%$ quota is very similar to the distribution in a setting with unlimited REDD+ usage (see Panel B in Figure 3), while the distribution with a $10 \%$ quota partly overlaps with the benchmark distribution without REDD+.

\subsubsection{Price stabilization policy}

In virtually all emissions trading programs policy makers have been concerned about permit prices that are either too low or too high (Goulder, 2013). A particular concern relates to the potential difficulties of firms to make investment decisions when the prices of permits (and the associated costs of compliance and abatement) are volatile and subject to uncertainty (see e.g. Blyth et al., 2007; Hepburn, 2006). The idea that significant swings in permit prices should be avoided, led many cap-and-trade program designers (e.g. in California, RGGI and Australia) to include mechanisms to stabilize permit prices at economically and politically tolerable levels. The most obvious provision to limit price variations is to set a price floor and ceiling, i.e. a so-called price collar. This type of price stabilization mechanism is investigated in this section.

Price collars could in principle be implemented either in the cap-and-trade market (i.e. for permits) or in the offset scheme (i.e. for credits). For permits, the price ceiling is achieved through provision of more allowances at a predetermined price, while the regulator could set a price floor either through a minimum auction reserve price or through commitment to buy and retire allowances at the predetermined floor price (Fell et al., 2012a). Credit price collars/floors have been considered e.g. in the context of the Australian emissions trading scheme, where one option of implementing such a floor would have been to require a fee on conversion of an offset into a unit equivalent to a domestic permit, if the price of the offset is below the floor price. Alternatively, an Australian government agency could have bought offsets at going rates and sold to domestic emitters at the same price as the market price or reserve price for Australian permits (Jotzo, 2011).

We model both price stabilization options. For the sake of analysis, we consider a permit and credit floor of $\underline{P}^{P}=5 \mathrm{US} \$ /$ ton $\mathrm{CO}_{2}$ and $\underline{P}^{R}=2 \mathrm{US} \$ /$ ton $\mathrm{CO}_{2}$, respectively (i.e. $50 \%$ of the respective starting price). The ceiling is set to $\bar{P}^{P}=\bar{P}^{R}=40 \mathrm{US} \$ /$ ton $\mathrm{CO}_{2}$. In line with real-world price collars, these price levels increase over time (by $5 \%$ p.a.). ${ }^{21}$ Given our above finding that low volatility regimes are conducive to low-carbon investments, the introduction of price collars in general should have a positive impact on wind investments. However, we have also shown that it is the credit price volatility that is almost exclusively driving the result. It is precisely for this reason interesting to investigate the

\footnotetext{
${ }^{20}$ We do not discuss the REDD+ offset usage in the quota policy scenarios because they simply reflect the patterns observed in section 3.1.2.

${ }^{21}$ We have also experimented with different calibrations (in particular, a higher floor price), but results remain qualitatively similar.
} 
effects of a credit price collar.

Panel B of Figure 4 shows the wind investment behavior for the two price collar scenarios (and for comparison again the results from the no-quota baseline and the no-offset benchmark). While the permit price collar has only a very limited effect on the probability to invest in wind, the credit price collar leads to a significantly higher wind investment share. With a minimum and maximum price for REDD+, the wind investment share reaches about $75 \%$ (compared to $85 \%$ in the case without REDD+). Yet, similar to the effect of lower volatility regime, the transition to the clean technology is delayed, as long as the option value exceeds the costs of waiting; the higher wind investment activity can only be observed after around period 30. These findings are in line with the above observation that the REDD+ price volatility dominates the investment effect, while the impact of permit price variability is negligible. Recall that the underlying reason for this asymmetry is that firms will in general have incentives to use the less expensive credits for compliance, which in turn explains why credit price uncertainty is the critical factor for investment decisions.

Panel B of Figure 5 also illustrates the benefits of REDD+ price collars in terms of risk diversification. We find that the impact of a price stabilization provision on firm's profits is very limited. Indeed, the profit distributions with and without an offset price collar are almost identical. The introduction of the price collar mainly seems to cut the extreme right tail of the distribution, reflecting the presence of the minimum price. Taken together, our results indicate that price stabilization mechanisms have strong positive effects on the investment behavior, while the impact on the profit spread is negligible. It is noteworthy that this impact is in contrast to the effect of a quota policy: with an offset quota there is a trade-off between higher wind investments and the profitability of firms.

While the finding that a price collar helps incentivizing investments in innovations is well established, we believe that our investigation of price collars in pollution control system with multiple compliance instruments (permits and credits) provides some new perspectives. To date only permit price collars are implemented in real-world cap-and-trade programs. We have shown, however, that in a policy regime in which offsets are relatively cheaper than permits, the classical permit price collar will not effectively change investment behavior. This finding reflects the fact that in a stylized real options model it is the volatility of the cheaper compliance instrument that is the driving force for investment. Under these conditions, a price collar for credits emerges as a largely overlooked policy option to foster investment incentives. ${ }^{22}$ From a political economy perspective, this is particularly interesting finding because the institutional feasibility of a price collar in an offset scheme rather than a cap-and-trade program may be significantly higher. Prior research indeed identified political feasibility as the major problem for the implementation of a permit price collar. ${ }^{23}$ This is because a price collar in an ETS may be interpreted as a tax; taxes however, as all fiscal measures, are subject to unanimity rules or supermajority requirements. It seems questionable whether a similar tax interpretation of a price collar in an offset scheme such as REDD+ is tenable. In the case of an offset scheme, it is rather likely that the benefits of providing a steady source of revenue are paramount, which may increase the political acceptability of a credit price collar.

\footnotetext{
${ }^{22}$ A notable exception is (Fell et al., 2012b) who explore an offset price collar mechanism in a dynamic abatement cost model.

${ }^{23}$ Recent discussions in the EU ETS are a prime example for the limited political feasibility of permit price collars (Knopf et al., 2014).
} 
Figure 5 - Profit distribution under different policy scenarios

Panel A: with REDD+ quota

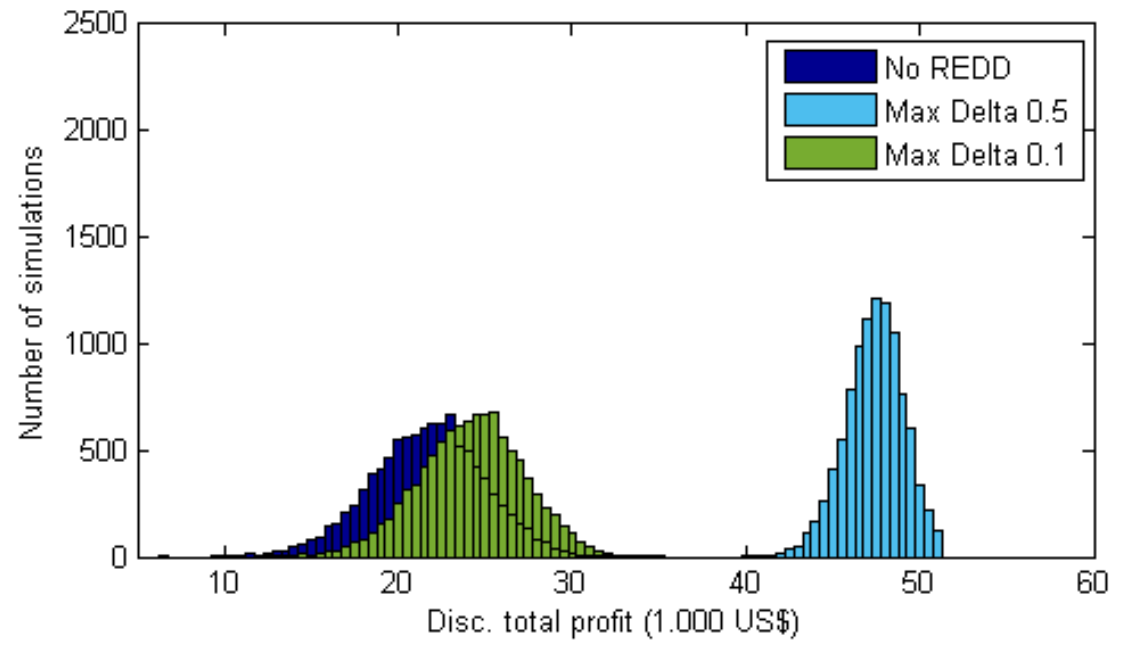

Panel B: with price collar

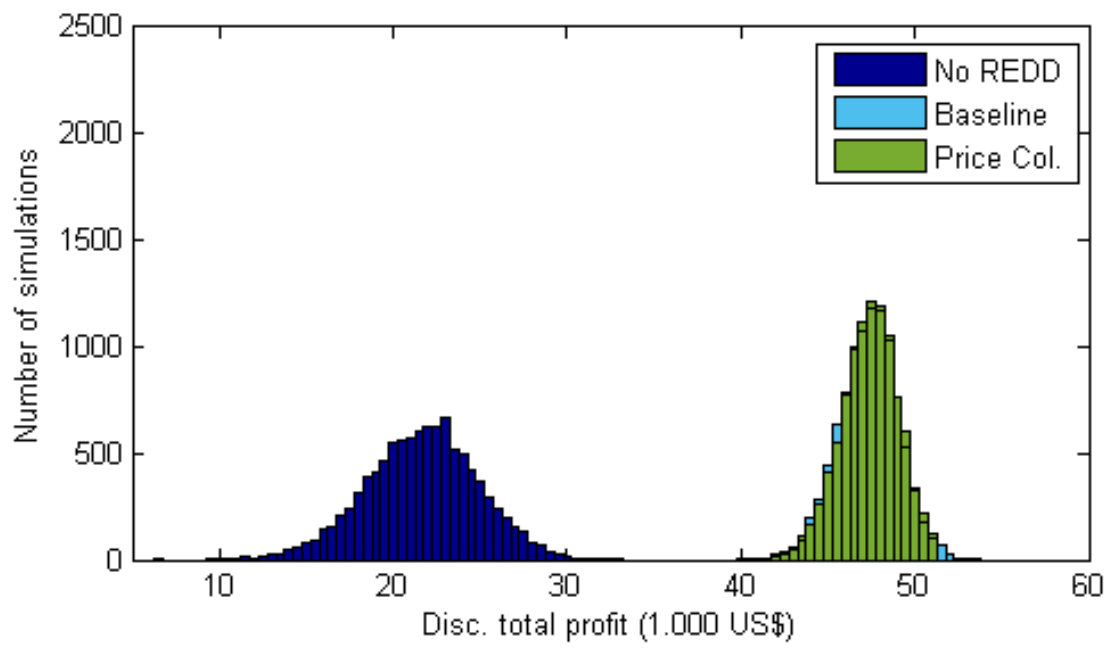

Panel C: with quota and price collar

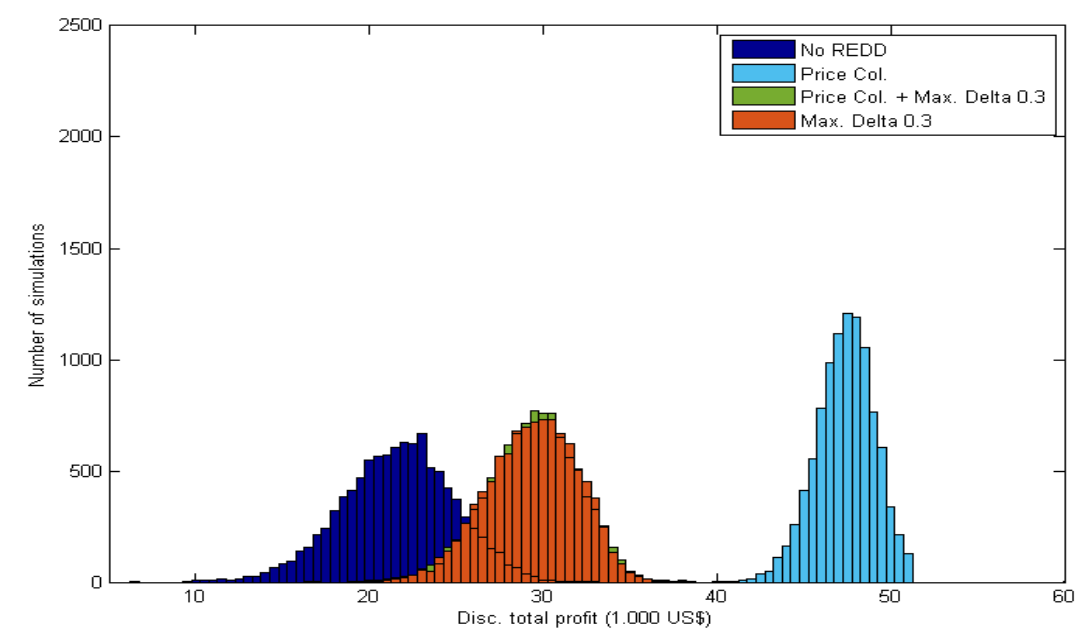




\subsubsection{Combination}

Finally, we consider the combination of an offset use limitation and a price collar. Given our finding that low offset quotas have beneficial features in terms of investment incentives but adverse effect on profits, we are particularly interested whether a combination of a higher offset quota with an offset price collar could deliver both investment incentives and risk diversification. For the sake of brevity, we focus on the specific combination of a $30 \%$ credit quota and a 2-40 US\$/ton $\mathrm{CO}_{2}$ credit price collar. Panel $\mathrm{C}$ of Figure 4 illustrates that wind investments over time under this policy design are very close to the investment pattern in an environment without offsets. A comparison to the wind investment share under an exclusive $30 \%$ quote in Panel $A$ shows that the gain of adding the price collar in term of higher investment is particularly pronounced towards the end of the planning period. In fact, the addition of the price collar ultimately ensures a wind investment share of about $85 \%$ as in the case without REDD+. If we also look at the profit distribution for this policy scenario (Panel C of Figure 5), we observe that the peak width of the profit distribution is slightly increasing. This observation indeed indicates a beneficial risk diversification effect of the quota-collar combination, although the magnitude of this effect remains limited. Summarizing, the additional benefits from introducing both a quota and price collar are significant though of moderate magnitude.

\section{Conclusions and policy implications}

The positive outcome of the most recent climate negotiations (COP21) in Paris could well lead to renewed interest in linking existing emissions trading systems (ETS) and emerging offset schemes. In that respect, REDD+ offsets represent one source of low cost abatement options. Concomitantly, allowing forestry offsets from less developed and emerging economies into existing and new ETS can strengthen international cooperation. Yet, such a strategy has been met with the concern that it could entail the risk of crowding out low-carbon investments of ETS-covered entities. Therefore, we use a real options model to investigate the investment behavior of a firm which can comply by using REDD+ credits or permits. We particularly focus on the impact of different designs of linking the credits into the permit trading scheme.

Our paper first investigates various scenarios of permit and offset price processes with differing volatility and correlation. The degree of correlation mainly depends on the pricing mechanism of offsets and whether it is market-based (then implying higher correlation with permits) or based on opportunity-costs, mainly reflecting forgone agricultural returns (reducing correlation). In a second step, we explore a broad range of policy design features, including offset quotas, price management mechanisms for permit and offset prices as well as a combination of both (all scenarios investigated and results are summarized in Table 5 below).

Unsurprisingly, our results confirm the investment crowding-out effect when ETS-covered entities have access to cheaper REDD+ credits. Although renewables investment (here represented by a wind park of the size comparable to the existing coal-fired capacity of a typical firm) increases over time, the speed of transition and the magnitude of the investment frequency are higher when firms do not have the access to cheaper offsets that allow them to postpone the transition while still being in compliance. Yet, several important insights on price processes emerge from our results. First, low-carbon investment critically depends on price volatility. We find significantly more investment with lower volatility. On the contrary, highly volatile ETS and REDD+ prices entail a higher risk of carbon lock-in, as the transition to less carbon-intensive energy is delayed. In a nutshell, higher price certainty 
incentivizes investment in the capital-intensive, yet low-carbon technologies. Second, wind investment also responds positively - though to a very limited extent - to the degree of price correlation. This reflects the risk diversification opportunity provided by lower correlation, which increases the attractiveness of postponing clean investments in the face of carbon price uncertainty, thus representing a benefit to society by offering a less risky transition pathway for decarbonizing energy supply.

The choice of policy design has likewise essential implications. We first investigate different quota levels for REDD+ credits as it was implemented for CDM in the majority of existing ETS. Our findings confirm that lower quotas significantly reduce the crowding-out effect on wind investment. Interestingly, for low quota levels (for instance $5 \%$ and $10 \%$ ) investment behavior is virtually identical. In addition, we show that access to offsets impacts positively the level of firm profits while reducing uncertainty. We then explore various price management provisions, also reflecting policy choices made - or being under discussion - in several jurisdictions. We find that a permit price collar with unrestricted offset access does not avoid the crowding-out of wind investment. Yet, applying the same price management instrument to REDD+ credits increases wind deployment significantly. We then propose a so far overlooked policy design combining a relatively high offset quota with a price collar for those REDD+ offsets. Interestingly, we show that such design leads to much higher wind investment and a level of wind deployment at the end of the period (almost identical to a regime without access to offsets). It also has a moderate but positive impact on firm profit levels. From a political economy perspective, this option has the advantage of limiting price intervention in the compliance market while ensuring a minimum return to REDD+ offset sellers.

This implies for policy, that the risk-hedging benefits of allowing REDD+ credits into an ETS can be reaped without jeopardizing the transition to low-carbon energy supply. At the same time, it provides a good basis for linking carbon-reduction efforts in tropical nations with emissions trading activities in industrialized countries, thereby increasing climate finance for REDD+ and allowing for a more efficient decarbonization pathway.

Linking REDD+ to existing carbon markets could thus be a promising approach to strengthen the global climate architecture, while potentially reducing the compliance costs of regulated entities. However, policymakers will have to pay close attention to the exact policy design, in particular considering offset quota, stabilization mechanisms for credit price as well as the appropriate mechanism to price REDD+ credits. Furthermore, REDD+ is only one source of potential offsets and even though the analysis presented in this study relies on calibration to prices and policy designs discussed in the REDD+ context, similar conclusions would apply to broader linking with offset schemes, e.g. from agriculture. 
Table 5 - Overview of results of all scenarios of market and policy designs, volatility and correlation regimes

\begin{tabular}{|c|c|c|}
\hline \multicolumn{3}{|c|}{ Benchmark scenarios: no access to offsets } \\
\hline \multicolumn{2}{|l|}{ Price process } & \multirow{3}{*}{$\begin{array}{l}\text { Results } \\
\text { - Higher wind investment with lower volatility of permit and } \\
\text { offset prices } \\
\text { - Offset price volatility drive investment results }\end{array}$} \\
\hline \multirow[t]{2}{*}{$\Delta$ Volatility } & $\begin{array}{l}\text { Permits (low- } \\
\text { medium-high) }\end{array}$ & \\
\hline & $\begin{array}{l}\text { Credits (low- } \\
\text { medium-high) }\end{array}$ & \\
\hline \multirow[t]{2}{*}{$\Delta$ Correlation } & $\begin{array}{l}\text { Market-based } \\
\text { (high) }\end{array}$ & \multirow[t]{2}{*}{$\begin{array}{l}\text { - Higher wind investment with higher correlation (i.e. with } \\
\text { market-based pricing of REDD+ offsets) }\end{array}$} \\
\hline & $\begin{array}{l}\text { OC-based } \\
\text { (low) }\end{array}$ & \\
\hline \multicolumn{3}{|c|}{ Policy scenarios (price baseline: high correlation, medium volatility) } \\
\hline $\begin{array}{l}\text { REDD+ offsets } \\
\text { quota }\end{array}$ & \multicolumn{2}{|l|}{ Results } \\
\hline $5 \%$ & \multirow{4}{*}{\multicolumn{2}{|c|}{$\begin{array}{l}\text { - Wind investment decreasing in quota } \\
\text { - At low quota levels (5-10\%) investment behavior quasi identical and } \\
\text { convergence to investment behavior without offsets at the end of period (but } \\
\text { with a delay) } \\
\text { - Firm profit levels increasing in quota } \\
\text { - Profit distribution narrowing in quota }\end{array}$}} \\
\hline $10 \%$ & & \\
\hline $30 \%$ & & \\
\hline $50 \%$ & & \\
\hline $\begin{array}{l}\text { Price } \\
\text { management }\end{array}$ & \multicolumn{2}{|l|}{ Results } \\
\hline $\begin{array}{l}\text { Permit price } \\
\text { collar }[5-40 \\
\text { US\$/ton } \mathrm{CO}_{2}, 5 \% \\
\text { p.a.] }\end{array}$ & \multicolumn{2}{|c|}{ - No/very limited impact on wind investment } \\
\hline $\begin{array}{l}\text { Credit price collar } \\
{[2-40 \text { US\$/ton }} \\
\left.\mathrm{CO}_{2}, 5 \% \text { p.a. }\right]\end{array}$ & \multicolumn{2}{|c|}{$\begin{array}{l}\text { - Higher wind investment } \\
\text { - Very limited impact on firm profit level }\end{array}$} \\
\hline $\begin{array}{l}\text { REDD+ offset } \\
\text { quota and price } \\
\text { management }\end{array}$ & \multicolumn{2}{|l|}{ Results } \\
\hline $\begin{array}{l}\text { Credit price collar } \\
{[2-40 \text { US\$/ton }} \\
\mathrm{CO}_{2}, 5 \% \text { p.a.] and } \\
30 \% \text { quota }\end{array}$ & \multicolumn{2}{|c|}{$\begin{array}{l}\text { - Higher wind investment } \\
\text { - Almost identical wind deployment than with no access to offsets at the end } \\
\text { of period but slower transition speed } \\
\text { - Moderate but positive impact on firm profit level }\end{array}$} \\
\hline
\end{tabular}




\section{Acknowledgments}

At MCC and IIASA, the research leading to these results has received funding from the Norwegian Agency for Development Cooperation (NORAD) under the project "Options Market and Risk-Reduction Tools for REDD". At PIK, the research leading to these results has received funding from the EU's Seventh Framework Programme (FP7/2007-2013) under grant agreement no. 308481 (ENTR'ACTE). We would like to thank all project participants - especially Jana Szolgayová for her modeling advice at the start of the project - and Frank Convery at EDF for valuable feedback to previous drafts.

\section{References}

Angelsen, A., \& Rudel, T. K. (2013). Designing and implementing effective REDD+ policies: A forest transition approach. Review of Environmental Economics and Policy, 7(1), 91-113.

Blyth, W., Yang, M., \& Bradley, R. (2007). Climate policy uncertainty and investment risk. OECD Publishing.

Bodansky, D., Hoedl, S., Metcalf, G., \& Stavins, R. (2014). Facilitating Linkage of Heterogeneous Regional, National, and Sub-National Climate Policies Through a Future International Agreement. National, and Sub-National Climate Policies Through a Future International Agreement (November 1, 2014). Retrieved from http://belfercenter.ksg.harvard.edu/files/harvard-ieta-linkage-paper-nov-2014.pdf

Bosetti, V., Lubowski, R., Golub, A., \& Markandya, A. (2011). Linking reduced deforestation and a global carbon market: implications for clean energy technology and policy flexibility. Environment and Development Economics, 16(04), 479-505.

Braun, N., Fitzgerald, T., \& Pearcy, J. (2014). Tradable Emissions Permits with Offsets. Available at SSRN 2434984. Retrieved from http://papers.ssrn.com/sol3/papers.cfm?abstract_id=2434984

Busch, J., Strassburg, B., Cattaneo, A., Lubowski, R., Bruner, A., Rice, R., ... Boltz, F. (2009). Comparing climate and cost impacts of reference levels for reducing emissions from deforestation. Environmental Research Letters, 4(4), 044006.

Dixit, A. K., \& Pindyck, R. S. (1994). Investment under uncertainty. Princeton university press.

Dormady, N. C., \& Englander, G. (n.d.). Carbon allowances and the demand for offsets: a comprehensive assessment of imperfect substitutes. Journal of Public Policy, 1-29.

Edenhofer, O., Flachsland, C., Stavins, R., \& Stowe, R. (2013). Identifying Options for a New International Climate Regime Arising from the Durban Platform for Enhanced Action. Harvard Project on Climate Agreements, Cambridge.

Engel, S., Pagiola, S., \& Wunder, S. (2008). Designing payments for environmental services in theory and practice: An overview of the issues. Ecological Economics, 65(4), 663-674.

Engel, S., Palmer, C., Taschini, L., \& Urech, S. (2015). Conservation Payments under Uncertainty. Land Economics, 91(1), 36-56.

European Commission. (2014). Impact assessment accompanying the document concerning the establishment and operation of a market stability reserve for the Union greenhouse gas emission trading scheme and amending Directive 2003/87/EC. Brussels: SWD(2014) 17 final. Retrieved from http://ec.europa.eu/clima/policies/ets/reform/docs/swd_2014_17_en.pdf

Fell, H., Burtraw, D., Morgenstern, R. D., \& Palmer, K. L. (2012a). Soft and hard price collars in a capand-trade system: A comparative analysis. Journal of Environmental Economics and Management, 64(2), 183-198. 
Fell, H., Burtraw, D., Morgenstern, R., \& Palmer, K. (2012b). Climate policy design with correlated uncertainties in offset supply and abatement cost. Land Economics, 88(3), 589-611.

Flachsland, C., Marschinski, R., \& Edenhofer, O. (2009). To link or not to link: benefits and disadvantages of linking cap-and-trade systems. Climate Policy, 9(4), 358-372. http://doi.org/10.3763/cpol.2009.0626

Fry, I. (2008). Reducing emissions from deforestation and forest degradation: opportunities and pitfalls in developing a new legal regime. Review of European Community \& International Environmental Law, 17(2), 166-182.

Fuss, S., Johansson, D. J., Szolgayova, J., \& Obersteiner, M. (2009). Impact of climate policy uncertainty on the adoption of electricity generating technologies. Energy Policy, 37(2), 733743.

Fuss, S., Szolgayova, J., Golub, A., \& Obersteiner, M. (2011). Options on low-cost abatement and investment in the energy sector: new perspectives on REDD. Environment and Development Economics, 16(04), 507-525. http://doi.org/10.1017/S1355770X10000410

Goulder, L. H. (2013). Markets for Pollution Allowances: What Are the (New) Lessons? The Journal of Economic Perspectives, 87-102.

Green, J. F., Sterner, T., \& Wagner, G. (2014). A balance of bottom-up and top-down in linking climate policies. Nature Climate Change, 4(12), 1064-1067. http://doi.org/10.1038/nclimate2429

Grosjean, G., Acworth, W., Flachsland, C., \& Marschinski, R. (2014). After monetary policy, climate policy: is delegation the key to EU ETS reform? Climate Policy, (ahead-of-print), 1-25.

Hepburn, C. (2006). Regulation by prices, quantities, or both: a review of instrument choice. Oxford Review of Economic Policy, 22(2), 226-247.

Hood, C. (2010). Reviewing existing and proposed emissions trading systems.

ICE Futures Europe. (2015). Retrieved from https://www.theice.com/futures-europe

International Carbon Action Partnership. (n.d.). ETS Map. Retrieved from https://icapcarbonaction.com/ets-map

International Energy Agency (IEA). (2010). Projected Costs of Generating Electricity 2010 Edition. Retrieved from https://www.iea.org/publications/freepublications/publication/projected_costs.pdf

Jotzo, F. (2011). A price floor for Australia's emissions trading scheme? Available at SSRN 1852865.

Kerr, S. C. (2013). The economics of international policy agreements to reduce emissions from deforestation and degradation. Review of Environmental Economics and Policy, 7(1), 47-66.

Kindermann, G., Obersteiner, M., Sohngen, B., Sathaye, J., Andrasko, K., Rametsteiner, E., ... Beach, R. (2008). Global cost estimates of reducing carbon emissions through avoided deforestation. Proceedings of the National Academy of Sciences, 105(30), 10302-10307.

Knopf, B., Koch, N., Grosjean, G., Fuss, S., Flachsland, C., Pahle, M., ... Edenhofer, O. (2014). The European Emissions Trading System (EU ETS): Ex-Post Analysis, the Market Stability Reserve and Options for a Comprehensive Reform. FEEM Nota Di Lavoro, 79.2014.

Koch, N., Fuss, S., Grosjean, G., \& Edenhofer, O. (2014). Causes of the EU ETS price drop: Recession, CDM, renewable policies or a bit of everything?-New evidence. Energy Policy, 73, 676-685.

Kossoy, A., Oppermann, K., Platonova-Oquab, A., Suphachalasai, S., Höhne, N., Klein, N., ... Wu, Q. (2014). State and Trends of Carbon Pricing 2014.

Kossoy, A., Peszko, G., Oppermann, K., Prytz, N., Klein, N., Blok, K., ... Borkent, B. (2015). State and Trends of Carbon Pricing 2015 (pp. 1-85). Retrieved from http://wwwwds.worldbank.org/external/default/WDSContentServer/WDSP/IB/2015/09/21/090224b083 OfOf31/2_0/Rendered/PDF/State0andOtrends0ofOcarbon0pricing02015.pdf 
Laing, T., Taschini, L., Palmer, C., Wehkamp, J., Fuss, S., \& Reuter, W. H. (2015). Understanding the demand for REDD+ credits.

Lubowski, R. N., \& Rose, S. K. (2013). The potential for REDD+: Key economic modeling insights and issues. Review of Environmental Economics and Policy, 7(1), 67-90.

McKibbin, W. J., Morris, A. C., \& Wilcoxen, P. J. (2008). Expecting the unexpected: Macroeconomic volatility and climate policy. Brookings Global Economy and Development Working Paper, (28).

Murray, B. C., Lubowski, R. N., \& Sohngen, B. L. (2009). Including international forest carbon incentives in climate policy: understanding the economics. Nicholas Institute for Environmental Policy Solutions, Duke University Durham, NC, USA.

Naegele, H. (2015). Offset credits in the EU ETS: A quantile estimation of firm-level transaction costs. Discussion Papers, Deutsches Institut für Wirtschaftsforschung.

Neuhoff, K., Schopp, A., Boyd, R., Stelmakh, K., \& Vasa, A. (2012). Banking of surplus emissions allowances: Does the volume matter?

Newell, R. G., Pizer, W. A., \& Raimi, D. (2014). Carbon market lessons and global policy outlook. Science, 343(6177), 1316-1317.

Ostrom, E. (2009). A polycentric approach for coping with climate change. Available at SSRN 1934353. Retrieved from http://papers.ssrn.com/sol3/papers.cfm?abstract_id=1934353

Ranson, M., \& Stavins, R. (2014). Linkage of greenhouse gas emissions trading systems: Learning from experience. National Bureau of Economic Research.

Recio, M. E. (2013). The Warsaw Framework and the Future of REDD+. Yearbook of International Environmental Law, 24(1), 37-69.

Reuter, W. H., Fuss, S., Szolgayová, J., \& Obersteiner, M. (2012). Investment in wind power and pumped storage in a real options model. Renewable and Sustainable Energy Reviews, 16(4), 2242-2248.

Szolgayova, J., Fuss, S., \& Obersteiner, M. (2008). Assessing the effects of $\mathrm{CO} 2$ price caps on electricity investments-A real options analysis. Energy Policy, 36(10), 3974-3981. http://doi.org/10.1016/j.enpol.2008.07.006

Trotignon, R. (2012). Combining cap-and-trade with offsets: lessons from the EU-ETS. Climate Policy, 12(3), 273-287.

Tuerk, A., Mehling, M., Flachsland, C., \& Sterk, W. (2009). Linking carbon markets: concepts, case studies and pathways. Climate Policy, 9(4), 341-357. http://doi.org/10.3763/cpol.2009.0621

Wehkamp, J., Aquino, A., Fuss, S., \& Reed, E. W. (2015). Analyzing the perception of deforestation drivers by African policy makers in light of possible REDD+ policy responses. Forest Policy and Economics, 59, 7-18. 


\section{Appendix}

Figure A1: Investment probability under different volatility regimes

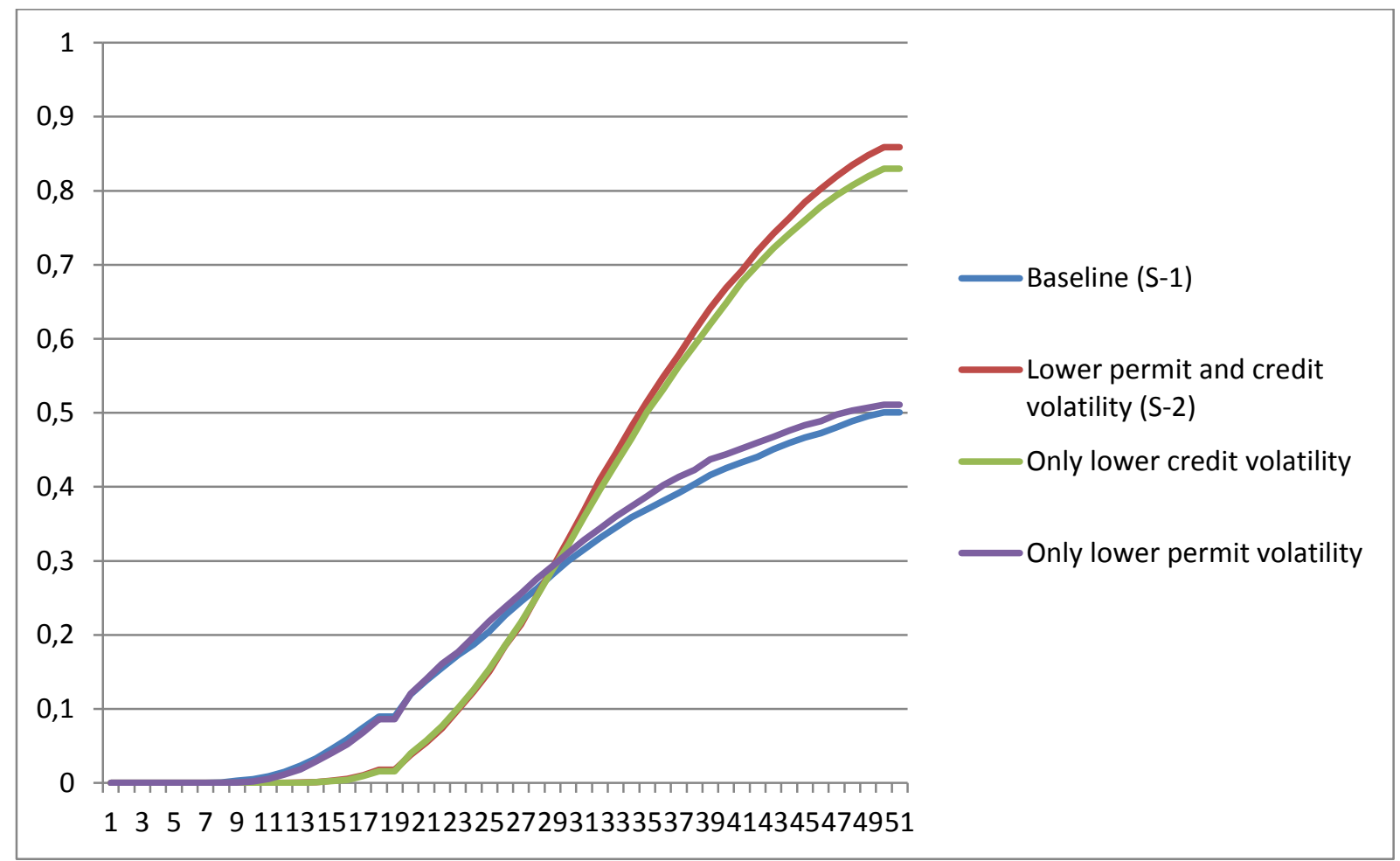

